\title{
Productive formations ranking methodology in order to select the optimal developing system
}

\author{
A.A. Farukshin \\ Postgraduate student, Saint-Petersburg Mining University, Saint-Petersburg, Russia
}

A.M. Zharkov

Doctor of geological and mineralogical Sciences, Saint-Petersburg Mining University, Saint-Petersburg, Russia

M.G. Ayrapetyan

Postgraduate student, Saint-Petersburg Mining University, Saint-Petersburg, Russia

\begin{abstract}
The article describes the methodology for ranking the objects of development of the Lower Cretaceous deposits of Western Siberia for their further development. The ranking is based on the degree of knowledge assessment of oil and gas deposits and allows us to predict the degree of uncertainty in determining the amount of reserves, which directly affects the field development system. The technique is universal, and its criteria are flexible. This allows us to adjust the estimate for deposits with varying degrees of knowledge.
\end{abstract}

Keywords: geological modeling, multivariate formation evaluation, geological uncertainties, formations ranking, saturation modeling

\section{INTRODUCTION}

In recent years, the majority of oil-producing regions (Volga-Ural, Western Siberia, etc.) have been characterized by the entry of the main pool of deposits into the late stage of development, where the extraction of residual hydrocarbon $(\mathrm{HC})$ reserves requires high unit costs. This, in turn, leads to a decrease in both the oil production rate and the efficiency of oilproducing enterprises. At the same time, the oil and gas industry still occupies one of the priority places in the Russian economy, contributing significantly to the development of other industries. One of the main ways to stabilize the rate of hydrocarbon production is to conduct exploratory work, the result of which is the discovery of new oil and gas fields.

However, in the "old" oil and gas producing regions, a decrease in the efficiency of prospecting is currently observed, which is associated with their relocation to areas with less prospects for oil and gas potential. In addition, work is being moved to areas with complex seismic and geological conditions with an increase in the number of small-scale deposits introduced into deep exploratory drilling. Obviously, drilling of unproductive facilities leads to economic losses. With this in mind, the task of prospecting for oil and gas is to obtain the most reliable information about the presence or absence of oil and gas-bearing object and its main characteristics.

This problem can be most rationally solved precisely by statistical methods based on a detailed study of the laws of structure and the criterion for evaluating small (1 to 5 million tonnes) and very small (less than 1 million ton) oil and gas deposits. Based on the analysis and systematization of factual material using multidimensional statistics, it is necessary to build geological models that provide the most rational choice of deposits for their input into further development. Ultimately, the effectiveness of prospecting will depend on the reliability of the economic planning of investment projects. The validity of the latter, first of all, is determined by the reliability 


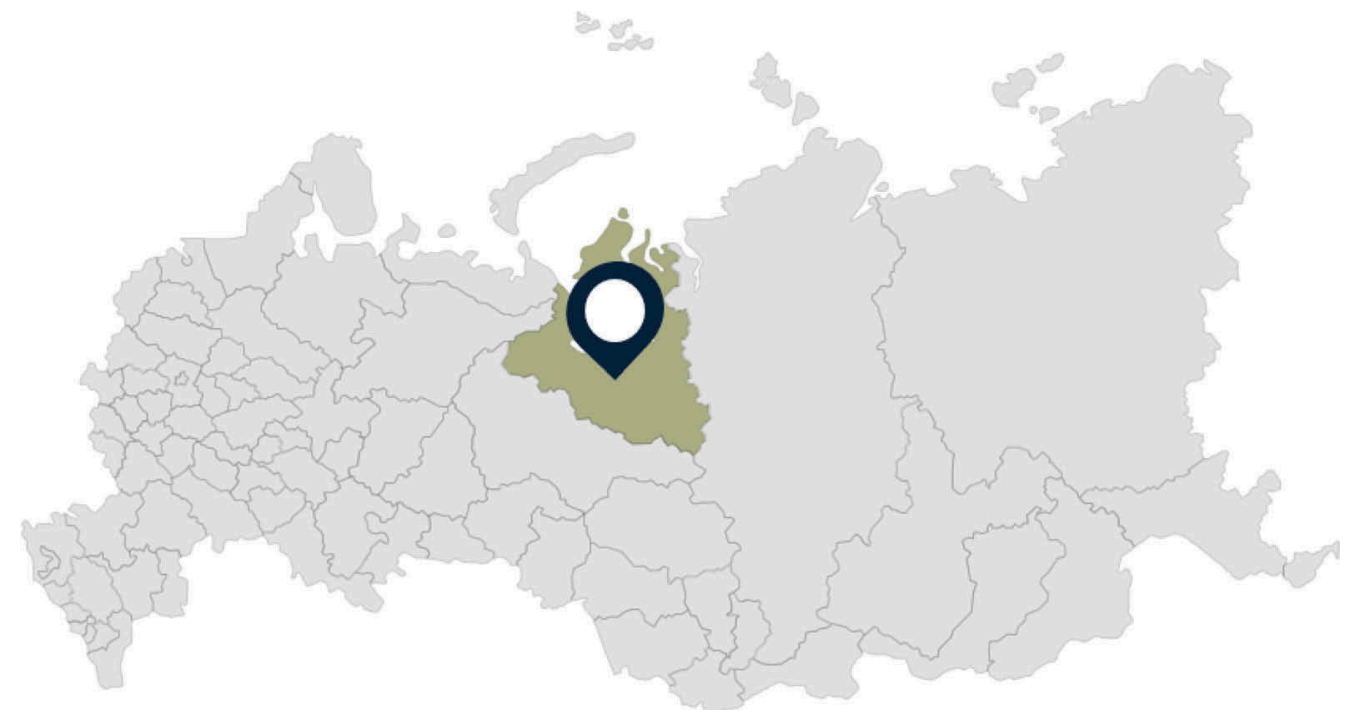

Figure 1. Research region.

of estimates of oil and gas reserves. The proposed approach allows even before significant investments to be made, to numerically assess the geological risks of exploration in Western Siberia, ensuring a reduction in the volume of exploration works by assessing uncertainties.

It is necessary either to discover new deposits, or to involve earlier discovered smaller deposits in the development, the commissioning of which is accompanied by large uncertainties in reserves, which causes concern when deciding on drilling or carrying out heavy geological and technical measures (GTM). Developers usually commission deposits from the bottom-up method; the choice is made according to the amount of residual recoverable reserves and the value of effective oil and gas saturated thicknesses. The same method accepts that, the value of reserves, this number is not fixed, but may vary within a certain interval.

Objects of research are undeveloped deposits of developed deposits and unexplored reserves of developed deposits of Lower Cretaceous deposits in Western Siberia (Figure 1).

\section{VERIFICATION OF GEOLOGICAL MODELS}

The goal of creating an algorithm for geological classification of formations was to create a unified scale for assessing the exploration of the hydrocarbon reservoir and forecasting the value of reserves with little exploration of hydrocarbon deposits. To compile a correctly working tool for ranking development objects, a geological analysis of all objects was carried out, as well as an analysis of their knowledge. For analysis, 12 deposits of the Snezhnoye field, which is at a late stage of development, were selected. All deposits are of the Lower Cretaceous age and are concentrated in the strata of the OK and AG groups. All deposits of the field are quite densely drilled by exploration and production wells. Detailed geological models were built for these deposits and hydrocarbon reserves (HC) were calculated. During the construction of geological models, data verification was carried out, which included: correlation of wells (Figure 2), construction of structural maps and thickness maps, derivation of the dependences of the permeability coefficient on the porosity coefficient, construction of a capillary model (Figure 3 ) for modeling oil saturation. Fluid contacts were also revised, because after drilling new wells the data were not updated. As a result, some substandard data were revealed, which were not taken into account when building dependencies and constructions.

The output was geological models that really reflected the structure of reserves, key uncertainties in their determination (Figure 4), as well as the distribution of hydrocarbon reserves. 


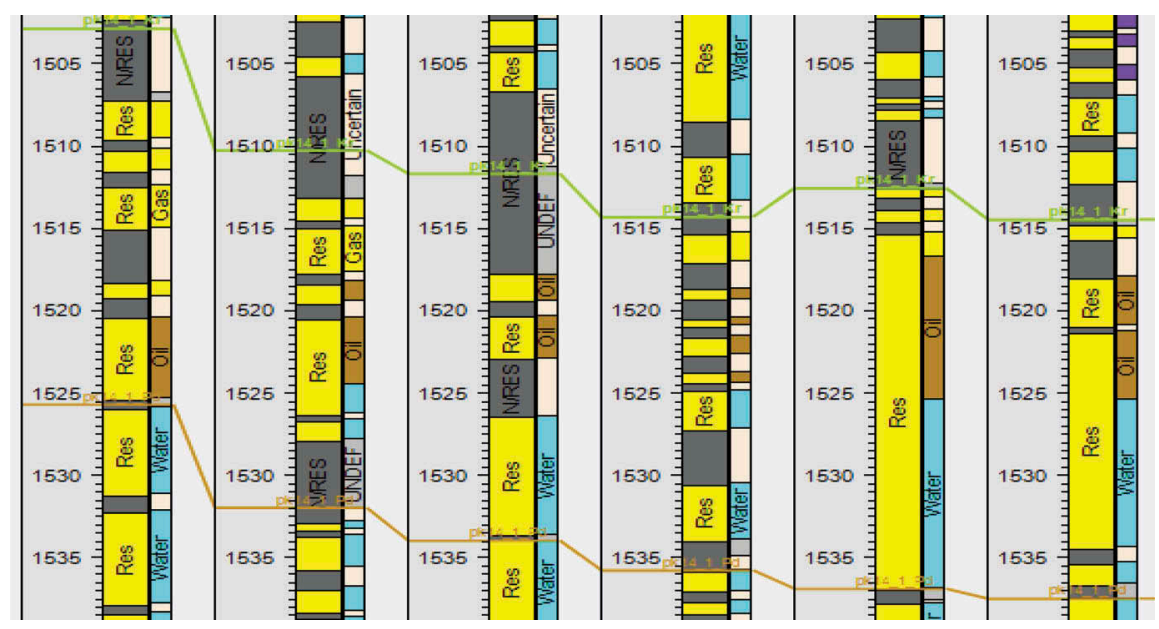

Figure 2. Correlation scheme of AK4 formation.

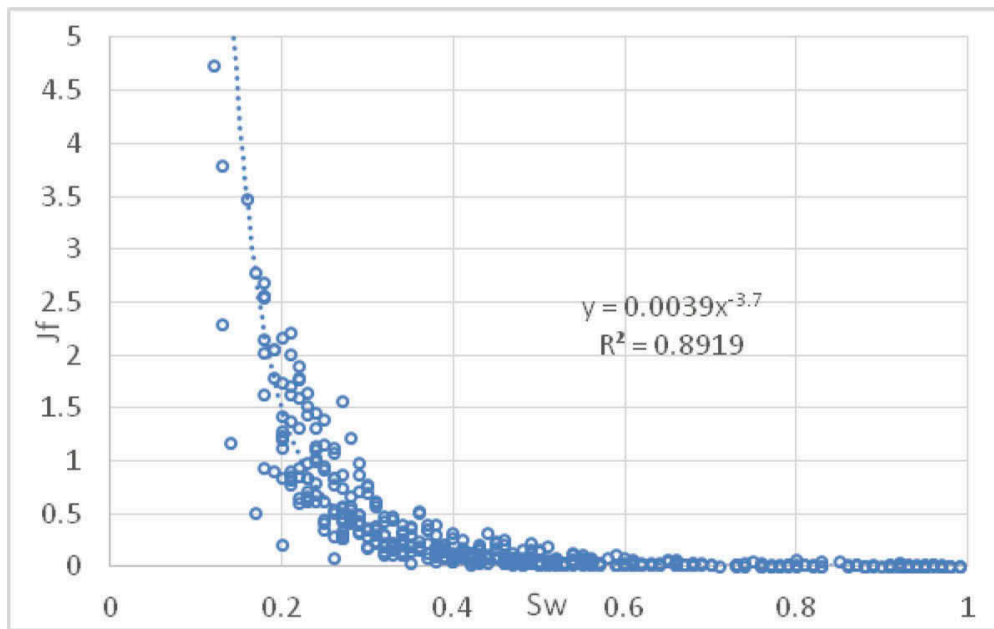

Figure 3. Capillary model (AK formations).

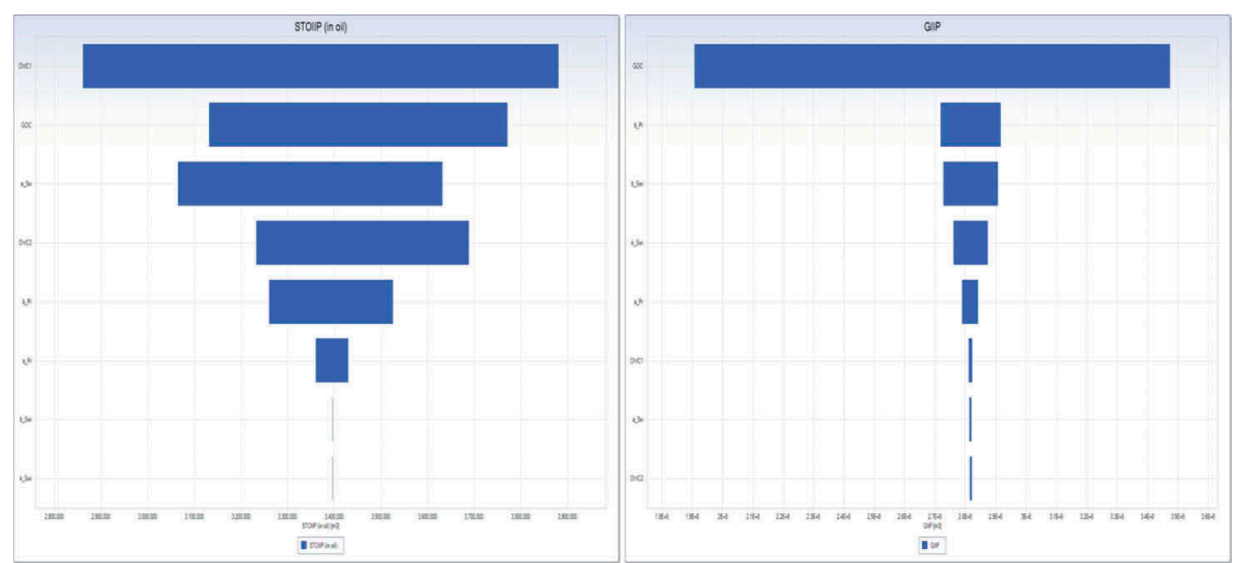

Figure 4. Sensitivity plot. OK2 formation reserves uncertainty decreases due to clarification of parameters. $\mathrm{HC}$ reserves more sensitive to varying of contacts and oil saturation. 

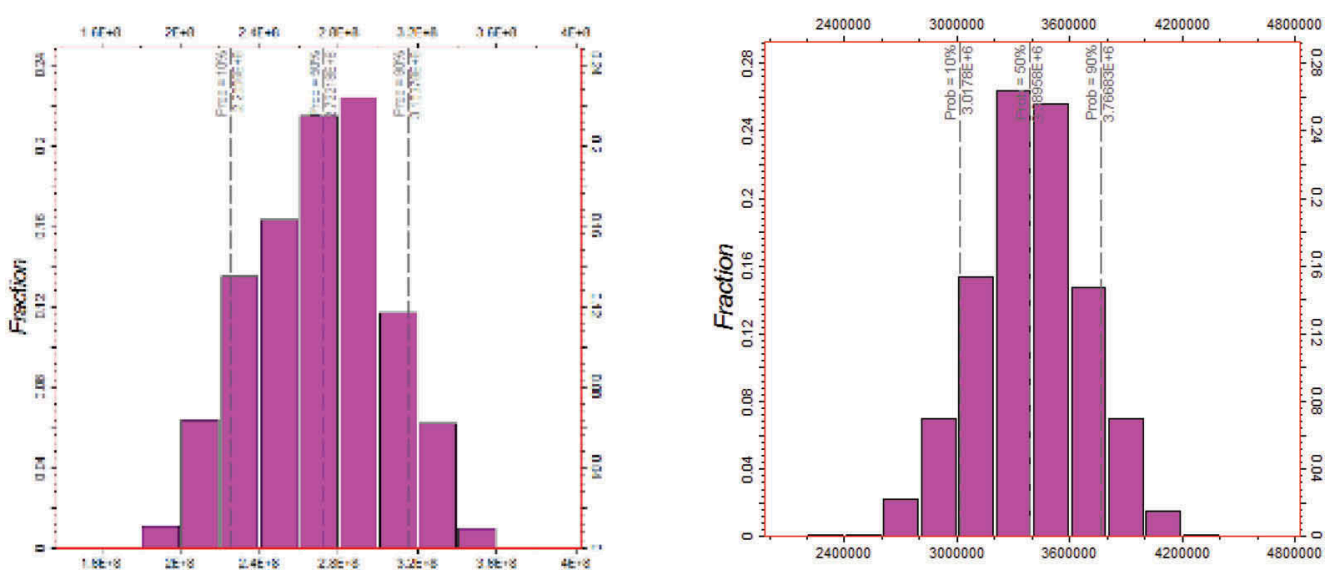

Figure 5. Clarification of initial oil reserves after remaking the geological model of OK2 formation.

The variability of reserves (Figure 5) was evaluated as a result of assessing the sensitivity of reserves to changes in the estimated parameters.

Thus, geological models were revised for all 12 sites. This was done to compile a reference sample that would allow us to develop a methodology for assessing the knowledge of development objects. Subsequently, all work was carried out on remade geological models with current data. For research, reserves of categories P10 (optimistic) and P90 (pessimistic) are useful.

\section{METHODOLOGY FOR THE KNOWLEDGE ASSESSMENT}

To assess the degree of knowledge of the development objects, a data pool was sorted, which somehow affects the uncertainties of hydrocarbon reserves. The study of deposits was considered as widely as possible and included:

1. Fluid studies

2. Petrophysical studies

3. Results of seismic data

4. Data from well tests and field geophysical data.

For each category of knowledge, parameters were described that describe the studies in detail. As a result, more than 80 parameters were collected that somehow contributed to the degree of knowledge of the reservoir. But it turned out that there are too many of these parameters to assess the degree of knowledge, since some of them strongly affect the calculated parameters, while others are not very. For example, the drilling density of a deposit affects the structure of the deposit, which in turn determines the area distribution and the size of reserves, and special geophysical studies, such as acoustic log data, do not affect the size of reserves so much.

Thus, directly related to the calculated parameters reservoir parameters were selected:

1. The structure of the deposits;

2. Fluid contact position;

3. Effective oil saturated thicknesses;

4. The coefficient of porosity $(\mathrm{Kp})$;

5. The coefficient of fluid saturation (So);

6. The formation volume factor (B);

Parameters for convenience are encoded with letters from A to F

The data characterizing the knowledge were grouped into categories and encoded from 0 to 5 :

1. Well stock;

2. Field geophysical surveys (FGS); 
3. Seismic surveys;

4. Well log data;

5. Petrophysical core studies;

6. Reservoir Fluid Studies;

As a result, a summary table was obtained for assessing the degree of exploration of deposits, on which the influence of studies on the determination of a particular parameter was analyzed (Table 1).

After compiling a summary table, evaluation criteria for each of its cells are developed. Cell A 0 - is determined by the degree of drilling density, A2 - by the correlation coefficient of the depth map with welltops. Cell B1 characterizes the knowledge of contacts by FGS, B3 - by well logs. $\mathrm{C} 0$ is determined by the drilling density (equal to A0), $\mathrm{C} 2$ is the correlation coefficient of the seismic data and thicknesses, C3 is the number of wells with a well logging. D2 - correlation coefficient of seismic data and Kp, D3 - correlation of core and well log data, D4 - presence of Kp core measurements. E3 - by correlation of the saturation parameter (Po) and So, E4 - by the presence of capillary studies and correlation of So with the capillary model.

To quantify the columns, the arithmetic mean for the parameters was calculated, but to take into account the weight of the studies, correction factors were also introduced:

$$
I=((a A 0+b A 2)+\ldots) / N
$$

where, I - knowledge, a and b - weighting factors.

All 12 deposits of the Snezhnoye field were estimated using this methodology (Figure 6).

Weight coefficients are independent.

Table 1. Criteria table for knowledge estimation. Green cells mean that study affects oil calculating parameters.

\begin{tabular}{lllllllll}
\hline & & Wells & Tests & Seismic data & Well log & Core & Fluids \\
\cline { 3 - 8 } Code & Parameter & 0 & 1 & 2 & 3 & 4 & 5 \\
\hline A & Structure & + & - & + & + & - & - \\
B & Contacts & - & + & - & + & - & - \\
C & Net thickness & + & - & + & + & + & - \\
D & Porosity & - & - & + & + & + & - \\
E & Saturation & - & - & - & + & + & - \\
F & B & + & - & - & - & - & + \\
\hline
\end{tabular}

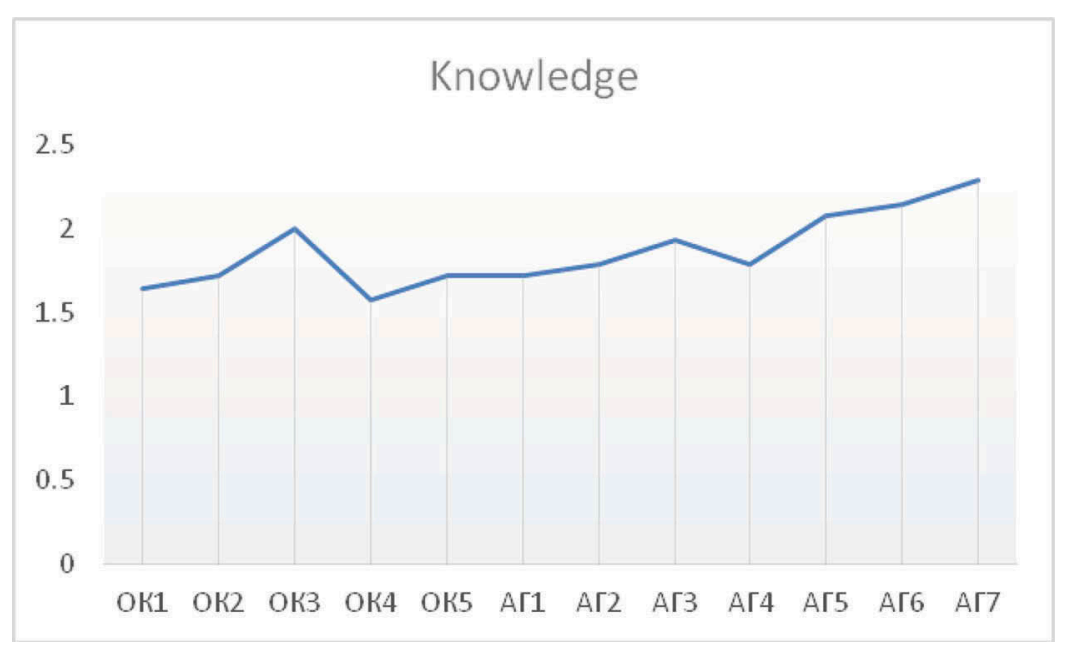

Figure 6. Formation knowledge. 


\section{RESULTS}

The weight coefficients for the studied deposits were selected automatically by solving the problem of multidimensional regression, when the degree of influence of each study on a particular parameter is calculated. The purpose of the selection was to obtain the maximum correlation coefficient of the degree of study and the ratio of reserves in the categories P10/ P90. This inventory ratio characterizes the uncertainty in the definition of reserves, that is, the wider the histogram of the distribution of reserves, the greater the uncertainty. As a result, a scattering diagram was obtained, the degree of correlation of which was 92\% (Figure 7). For 12 Snezhnoye deposits, the maximum weight factor was introduced for the So parameter and the contact position. Thus, all deposits are characterized by a strong sensitivity of the reserve uncertainty structure to these parameters.

\section{DISCUSSION}

This pattern of assessment of the degree of knowledge is universal for deposits. Depending on the degree of knowledge of the deposit for each cell in the table, you can set arbitrary numerical criteria, for example, for one field, the seismic data can describe the geological structure more detailed than for others.

This technique is designed to help the geologist in a number of tasks: the selection of the object of development from a variety of deposits for the purpose of priority, higher priority for further input into development, planning GTM; assessment the state of deposits knowledge allows assessing risks and uncertainties.

GTM planning on deposits with small and very small reserves is characterized by the presence of economic risk due to the possibility of a small economic effect.

The relevance of the method at the moment is that it allows the geologist to consider and type a new object in 1-2 hours. It can also be used for further studies of the object-timely update information in special checklists and get updated results instantly.

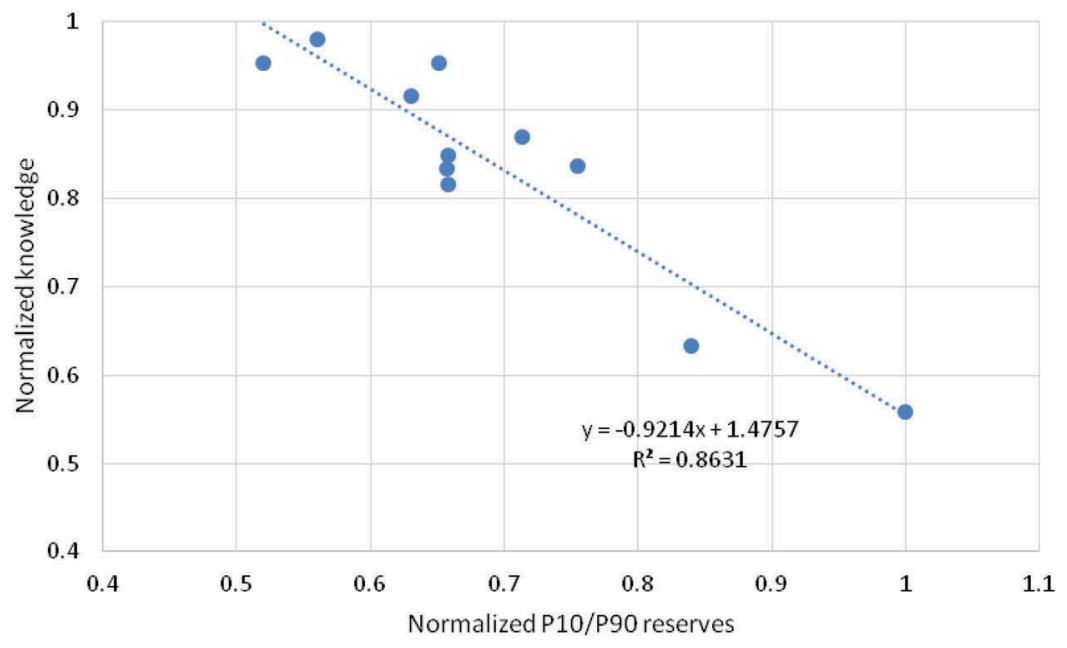

Figure 7. Normalized knowledge to P10/P90 reserves cross-plot. 


\section{CONCLUSIONS}

A method was developed for rapid assessment of the degree of knowledge of oil and gas deposits. The working tool is a table, which is a universal template for differentiating deposits depending on the availability, sufficiency, reliability and quality of input information. For a more accurate correlation of the study with the uncertainty in reserves, weight coefficients were automatically selected to determine the study that most affects them. The method was tested on 12 layers of the OK and AG group of the Snezhnoye field, the geological models of which were detailed in advance and the reserves of which were calculated by the probabilistic method. A high correlation coefficient $(92 \%)$ showed that the developed template accurately reflects the structure of uncertainty in hydrocarbon reserves. This means that after assessing the uncertainty of several deposits in detail, you can choose such criteria that can predict with high confidence the uncertainty of other deposits of the field of interest.

\section{REFERENCES}

Ababkov, K. (2010). Fundamentals of three-dimensional digital geological modeling. Ufa: "Oil and Gas business".

Bolshakov, M., Meynarands R., Naugunov M. V. "A new approach to the assessment of the index of complexity of development of deposits in Western Siberia". SPE-187780-RU

Disposal of the Ministry of Russia from 01.02.2016N 3-R (edition of 19. 04.2018) "On approval of methodological recommendations on application of Classification of reserves and resources of oil and combustible gases, approved by order of the Ministry of natural resources and ecology of the Russian Federation on 01.11.2013 N 477"

Gutman, I., Kuznetsova G. P. Classification of correlation of geological sections of wells in connection with the degree of study of oil and gas objects. Features of performance of comparison of geological sections of wells with use of the latest computer technologies. - Moscow: Gubkin Russian state University of oil and gas, 2006.

Matveev, V.P., Tarasenko, A.B. 2019. The study of the Berkha Island reef massif (Novaya Zemlya), based on lithological and geochemical data. - Chemie der Erde.

Prishchepa, O., Nefedov, Y., \& Grokhotov, E. 2019. Geochemical and petrophysical studies of hydrocarbon potential of domanic shale formation (Timan-Pechora petroleum province). EAGE/SPE Workshop on Shale Science 2019 - Shale Sciences: Theory and Practice

Rose, P. "Risk Analysis and management of oil and gas exploration projects" // SIC "RCD", "Izhevsk Institute of computer research", - Moscow-Izhevsk, 2011, - 304 p.

Sirotkin, A.N., Talovina, I.V., Duryagina, A.M. 2019. Mineralogy and geochemistry of alkaline lamprophyres of north-western Spitsbergen (Svalbard) - Chemie der Erde.

Zakrevsky, K. (2009). Geological 3D modeling. Moscow: LLC CPI Mask. 